Exercise Physiology

\title{
Running velocity at maximum oxygen uptake and at maximum effort: important variables for female military pentathlon
}

\author{
Míriam Raquel Meira Mainenti $^{1}$ (D), Patrícia dos Santos Vigário ${ }^{2}$ (D), Hugo Brito Batista ${ }^{1}$ (D), \\ Luiz Fernando Valverde Bastos $^{1}$ (D), Danielli Braga de Mello ${ }^{1}$ \\ ${ }^{1}$ Escola de Educação Física do Exército, Rio de Janeiro, RJ, Brazil; ${ }^{2}$ Centro Universitário \\ Augusto Motta, Rio de Janeiro, RJ, Brazil.
}

Associate Editor: Angelina Zanesco (D), ${ }^{1}$ Universidade Metropolitana de Santos, Faculdade de Medicina, Santos, SP, Brazil; 'Universidade Estadual Paulista "Júlio de Mesquita Filho", Departamento de Educação Física, Instituto de Biociências, Rio Claro, SP, Brazil. E-mail: angelina.zanesco@unesp.br.

\begin{abstract}
Aim: to correlate cardiopulmonary capacity widely used variables with athletic performance in $4 \mathrm{~km}$ cross country race, in elite female military pentathlon athletes. Methods: Five military pentathlon athletes from Brazilian team with $27.5[25.0 ; 29.3]$ years old underwent an incremental ramp treadmill test to determine $\mathrm{VO}_{2} \max , \mathrm{vVO}_{2} \max$ (velocity of initial $\mathrm{VO}_{2}$ plateau), maximum velocity, and these same variables in anaerobic threshold. Furthermore, the performance obtained on the cross-country race of the last trial before the world military games was recorded. Spearman's correlations were used to investigate the association between cardiopulmonary variables and athletic performance $(\mathrm{p}<0.05)$. Results: The athletes exhibited a median total body weight of $64.3[60.9 ; 66.6] \mathrm{kg}$ and height of 1.75 [1.66; $1.76] \mathrm{cm}$. Race performance was positively correlated with $\mathrm{vVO}_{2} \mathrm{max}(\mathrm{r}=0.98$, very strong correlation) and maximum velocity reached $(\mathrm{r}=0.95$, very strong correlation). The remaining cardiopulmonary variables did not show similar behavior, with $\mathrm{r}$ varying between -0.26 and 0.44 . Conclusion: Maximum velocity and $\mathrm{vVO}_{2} \max$ indicators are directly related to athletic performance in the $4 \mathrm{~km}$ cross country race of elite female military pentathlon athletes. Thus, the technical team must pay particular attention to athletic performance in these cardiopulmonary variables in both the selection of new athletes and the identification of the effectiveness of applied training strategies.
\end{abstract}

Keywords: physical education, exercise physiology, athletic performance, running, oxygen consumption.

\section{Introduction}

The military pentathlon was created in the 40's proposing the inclusion of typically military characteristics in a sports competition. It consists of five events: (i) shooting with a standard rifle $(200 \mathrm{~m})$; (ii) obstacle running (500 $\mathrm{m})$; (iii) obstacle swimming (50 m); (iv) grenade throwing: one event for precision and one for distance; and (v) cross country running $-8 \mathrm{~km}$ for men and $4 \mathrm{~km}$ for women. Points are awarded according to performance in each event and the competitor with the highest total number of points at the end is the winner ${ }^{1}$.

In recent years, the number of military pentathlon athletes taking part in competitions organized by the International Military Sports Council (CISM) has increased significantly, having the latest competition, in 2019, the participation of 26 teams from different countries around the world ${ }^{2}$. Besides the increasing number of military pentathlon athletes worldwide ${ }^{2}$, it has been continuously observed better technical and physical quality of the participants, making the competitions even harder. Thus, all strategies that could be used to improve performance in each event favoring the final result should be considered. In this case, it includes the identification of physiological variables to be manipulated in training.

Regarding each military pentathlon event, crosscountry running is the one in which the aerobic system is predominantly used and therefore, an optimal cardiopulmonary capacity is necessary to achieve good performance. The Cardiopulmonary Exercise Test (CPET) permits to direct assessment of the individual's cardiopulmonary capacity throughout the gas exchange and pulmonary ventilation analysis. The most CPET indices used to describe and improve aerobic performance are maximum oxygen consumption $\left(\mathrm{VO}_{2} \mathrm{max}\right)^{3-5}$, the lowest velocity at which $\mathrm{VO}_{2}$ plateau is observed $\left(\mathrm{vVO}_{2} \mathrm{max}\right)^{6,7}$, running economy ${ }^{8,9}$, anaerobic threshold, and exhaustion time in $\mathrm{vVO}_{2}(\mathrm{Tlim})^{7}$.

Several literature studies use these physiological indices to predict the aerobic performance of endurance runners and other sport modalities ${ }^{7-11}$, but none for military pentathlon. Furthermore, it is important to underscore 
that to date the samples of scientific articles have been composed of male subjects. The knowledge of which CPET variables are associated with athletic performance could help the technical team in both selections of new athletes and monitoring athletes' evolution over a season.

Thus, the present study aimed to correlate, in elite female military pentathlon athletes, the performance in the $4 \mathrm{~km}$ cross country running with physiological variables widely used to describe aerobic performance, here considered: $\mathrm{VO}_{2}$, heart rate, and running velocity at maximum and anaerobic threshold points, and $\mathrm{vVO}_{2}$ max.

\section{Methods}

\section{Study design and participants}

The present study was approved by a local ethics committee (protocol number CAAE: 49600515.0.0000.5235) and all participants gave their written informed consent before the study entry. From the six military pentathlon athletes who composed the female Brazilian military team in 2015, five were included in this cross-sectional study. Only one athlete refused to give her consent and thus was not included. All participants were aged 18 years or more and had the index to participate in the $6^{\text {th }}$ World Military Games, held in Korea, in 2015.

\section{Cardiopulmonary exercise test}

All participants were submitted to a maximal Cardiopulmonary Exercise Test (CPET) on a treadmill (Technogym Excite Run 700; Italy). The ramp protocol was applied as follows: (i) warm-up - three min at a velocity of $8.0 \mathrm{~km} / \mathrm{h}$; (ii) main part - successive increments of $0.4 \mathrm{~km} / \mathrm{h}$ every $30 \mathrm{~s}$ from the initial velocity of $8 \mathrm{~km} / \mathrm{h}$. The ramp characteristics were selected to ensure a test duration of between 8 and $12 \mathrm{~min}$, in line with American Heart Association guidelines ${ }^{12}$; and (iii) recovery - three min at $40 \%$ of maximum velocity.

It was verified whether the following pre-test instructions were adhered to: not engaging in exhausting physical activity on the same day of the test, not drinking alcoholic beverages or those containing caffeine since the previous night, and not smoking in the four hours preceding the CPET.

The expired gases were measured in the respirationrespiration mode, and stored as the average of three breaths, using the VO2000 metabolic gas analyzer (Medgraphics, USA) throughout the tests. The Aerograph 4.3 program (AeroSport Inc., USA), which displays and stores real-time ventilatory data, was applied.

The following cardiopulmonary variables were measured or calculated: oxygen consumption $\left(\mathrm{VO}_{2} ; \mathrm{mL} \cdot \mathrm{kg}^{-1}\right.$. $\mathrm{min}^{-1}$ ); heart rate (HR; bpm); and running velocity $(\mathrm{km} /$ h). These variables were analyzed at two moments of effort: (i) ventilatory anaerobic threshold and (ii) peak. If the athlete reached the $\mathrm{VO}_{2}$ plateau, the lowest plateau velocity, named $\mathrm{VO}_{2}$ max velocity $\left(\mathrm{vVO}_{2} \mathrm{max}\right)$, was also analyzed (13). Heart rate was continuously monitored with a RCX3 heart rate monitor (Polar, Finland).

The $\mathrm{VO}_{2}$ max was the highest mean of three $\mathrm{VO}_{2}$ values in the last min of the test when the plateau was characterized $^{3,14}$. The velocity observed at the moment that the $\mathrm{VO}_{2}$ increase was less than $0.5 \mathrm{~mL} / \mathrm{kg} / \mathrm{min}$ over $30 \mathrm{~s}$ and $/$ or less than $2 \mathrm{~mL} / \mathrm{kg} / \mathrm{min}$ over $2 \mathrm{~min}$ was called $\mathrm{vVO}_{2} \mathrm{max}$ (adapted from Bragada et al. ${ }^{13}$ ). When the formation of the plateau could not be observed, the velocity at which peak $\mathrm{VO}_{2}$ was recorded was used as $\mathrm{vVO}_{2} \max ^{14}$.

The participants of this study were verbally encouraged during the test. Blood pressure (BP) was also checked before and after the test in order to monitor the behavior of the cardiovascular system under stress and ensure the safety of the individual. Similarly, the modified Borg perceived exertion scale ${ }^{15}$ was used, ranging from 0 (absence of fatigue) to 10 (maximum fatigue), to assess the level of discomfort during the exercise.

The ventilatory threshold was identified using analysis of ventilatory equivalents for oxygen and carbon dioxide ( $\mathrm{VE} / \mathrm{VO}_{2}$ and $\mathrm{VE} / \mathrm{VCO}_{2}$, respectively). The moment of effort at which $\mathrm{VE} / \mathrm{VO}_{2}$ increased without a concomitant rise in $\mathrm{VE} / \mathrm{VCO}_{2}$ was considered the ventilatory threshold ${ }^{16}$. This identification was performed by two researchers.

\section{Cross-country running athletic performance}

Athletic performance in cross-country running was expressed in pentathlon points, according to the point conversion table, specific for this modality, and taking into account the time elapsed to complete $4 \mathrm{~km}$, in minutes and seconds. The better the performance the higher the score. Data were obtained from the championship in which the athletes who composed the Brazilian team in the $6^{\text {th }}$ World Military Games were selected.

\section{Statistical analysis}

Non-parametric strategies were elected due to the small sample size. Descriptive analyses were presented as median, $1^{\text {st }}$, and $3^{\text {rd }}$ quartiles, and minimum and maximum values. Spearman's correlations were used to investigate the association between cardiopulmonary variables and athletic performance in cross-country running, considering $\mathrm{VO}_{2 \max }, \mathrm{VO}_{2}$ at the ventilatory threshold, maximum velocity, the velocity at the ventilatory threshold, and $\mathrm{VO}_{2} \max$ velocity $\left(\mathrm{vVO}_{2 \max }\right)$. Correlation coefficient $(\mathrm{r})$ classification was: very strong for $r$ values $\geq 0.90$; strong for $0.6 \leq r$ $<0.9$; fair for $0.3 \leq \mathrm{r}<0.6$; and weak for $\mathrm{r}$ values $<0.3^{17}$.

All the analyses were carried out using the SPSS 13.0 (Chicago, IL, USA), and p-values $<0.05$ were considered statistically significant. 


\section{Result}

The athletes had a median age of 27.5 [25.0; 29.3] years, a total body mass of $64.3[60.9 ; 66.6] \mathrm{kg}$, and a height of $1.75[1.66 ; 1.76] \mathrm{m}$. Their routine consisted of six hours of training a day (including physical and technical training) and all the athletes were training the modality for more than two years. Descriptive analysis of cardiopulmonary variables during the CPET and athletic performance in the cross-country race are presented in Table 1. All of them achieved a score of 10 of perceived exertion (maximum fatigue) before interrupting the test.

The variables that were significantly correlated with athletic performance in the cross-country running were $\mathrm{vVO}_{2} \max (\mathrm{r}=0.98 ; \mathrm{p}=0.005)$ and maximum velocity $(\mathrm{r}=0.95 ; \mathrm{p}=0.014)$, as presented in Figures 1 and 2, showing a very strong correlation. The other variables

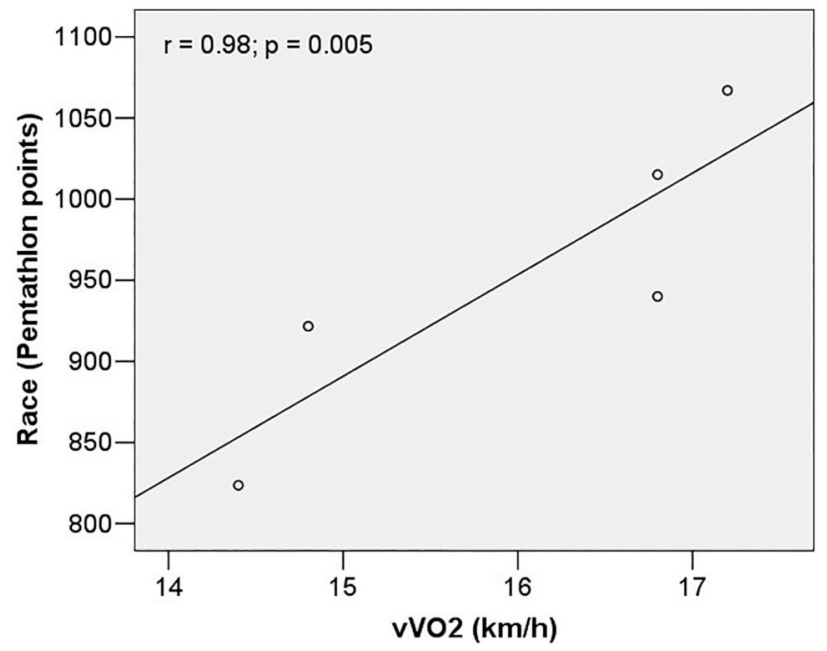

Figure 1 - Dispersion graph of $\mathrm{vVO}_{2}$ points (velocity at the start of the $\mathrm{VO}_{2}$ plateau) and performance in the race $(\mathrm{n}=5)$. The coefficient correlation $(r)=0.98$ is classified as very strong, showing a significant relationship between race performance and $\mathrm{vVO}_{2}$ max. exhibited correlation coefficients between -0.36 and 0.60 (Table 2).

\section{Discussion}

The purpose of this study was to determine which cardiopulmonary exercise capacity variables are more correlated to the $4 \mathrm{~km}$ cross-country performance of elite military pentathlon women athletes. The results indicated two variables as possible determinants of performance: velocity at the start of the $\mathrm{VO}_{2}$ plateau $\left(\mathrm{vVO}_{2} \max \right)$ and maximum velocity. This relationship has been widely investigated for other sports modalities ${ }^{7,18-21}$ with mainly aerobic characteristics, but never for military pentathlon athletes. With the increasing practice and number of athletes of this modality in military events, research should be

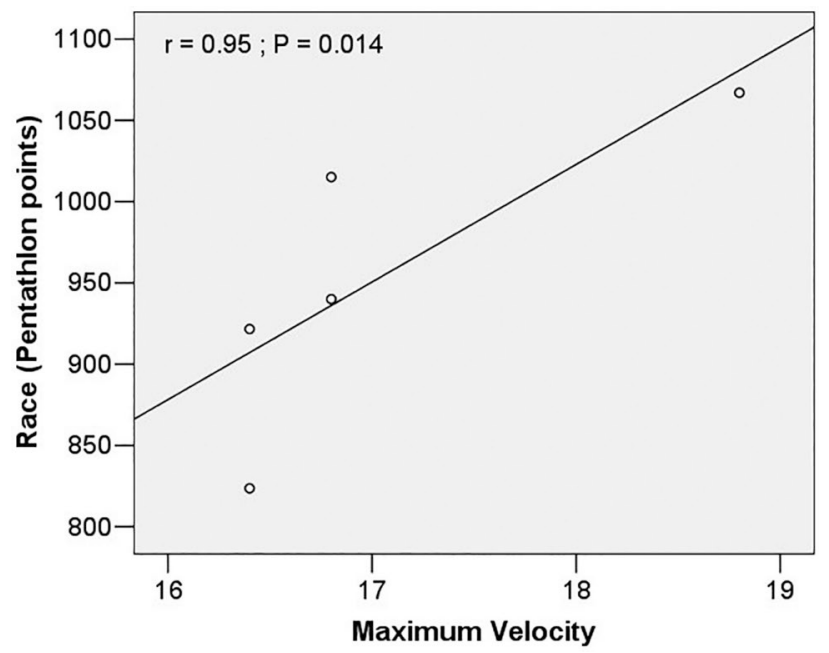

Figure 2 - Dispersion graph of maximum velocity and race performance points $(n=5)$. The coefficient correlation $(r)=0.95$ is classified as very strong, showing a significant relationship between $4 \mathrm{~km}$ cross country race performance and maximum velocity reached in the cardiopulmonary exercise test.

Table 1 - Cardiopulmonary behavior under exercise and athletic performance in military pentathlon athletes from the Brazilian Army (n=5).

\begin{tabular}{|c|c|c|}
\hline Variable & Median [ $1^{\text {st }}$ quartile- $3^{\text {rd }}$ quartile] & Minimum-Maximum \\
\hline Pre exercise HR (bpm) & $65.0[55.5-75.0]$ & $55-84$ \\
\hline VT vel $(\mathrm{km} / \mathrm{h})$ & $14.8[14.6-16.0]$ & $14.4-16-8$ \\
\hline VT HR (bbm) & $191.0[165.5-194.5]$ & $151.0-195.0$ \\
\hline $\mathrm{VT} \mathrm{VO} 2\left(\mathrm{~mL} \cdot \mathrm{kg}^{-1} \cdot \mathrm{min}^{-1}\right)$ & $40.2[38.5-46.0]$ & $37.2-47.9$ \\
\hline Max vel $(\mathrm{km} / \mathrm{h})$ & $17.0[16.4-17.9]$ & $16.4-18.8$ \\
\hline Max HR (bpm) & $196.0[175.0-199.0]$ & $170.0-202.0$ \\
\hline $\mathrm{VO}_{2} \max \left(\mathrm{mL} \cdot \mathrm{kg}^{-1} \cdot \min ^{-1}\right)$ & $44.8[39.7-51.3]$ & $39.1-54.7$ \\
\hline $\mathrm{vVO}_{2} \max (\mathrm{km} / \mathrm{h})$ & $15.6[14.5-17.0]$ & $14.4-17.2$ \\
\hline *Race performance (points) & $940.0[872.6-1041.0]$ & $823.6-1067.0$ \\
\hline
\end{tabular}

$\mathrm{HR}=$ heart rate; VT Vel: ventilatory anaerobic threshold velocity; VT HR $=$ heart rate at the ventilatory anaerobic threshold; $\mathrm{VT} \mathrm{VO}_{2}=\mathrm{oxygen}_{\mathrm{C}}$ consumption at the ventilatory anaerobic threshold; Max velocity = maximum velocity; Max $\mathrm{HR}=$ maximum heart rate; $\mathrm{VO}_{2} \max =\operatorname{maximum}$ oxygen consumption; $\mathrm{vVO}_{2} \max =$ lowest velocity at which oxygen consumption plateau is observed. * Race performance is expressed in "pentathlon points". The better the performance the higher the score. The athlete's score in pentathlon points is found on the race time conversion table. 
Table 2 - Correlations between cross country running points and CPET variables in military pentathlon athletes from the Brazilian Army ( $\mathrm{n}=5$ ).

\begin{tabular}{|c|c|c|}
\hline Variable & Spearman coefficient & Coefficient classification \\
\hline VT Vel $(\mathrm{km} / \mathrm{h})$ & 0.56 & fair \\
\hline VT HR (bpm) & -0.10 & weak \\
\hline $\mathrm{VT} \mathrm{VO} 2\left(\mathrm{~mL} \cdot \mathrm{kg}^{-1} \cdot \mathrm{min}^{-1}\right)$ & 0.60 & strong \\
\hline Max vel $(\mathrm{km} / \mathrm{h})$ & 0.95 & very strong \\
\hline Max HR (bpm) & -0.36 & fair \\
\hline $\mathrm{VO}_{2} \max \left(\mathrm{mL} \cdot \mathrm{kg}^{-1} \cdot \mathrm{min}^{-1}\right)$ & 0.30 & fair \\
\hline $\mathrm{vVO}_{2} \max (\mathrm{km} / \mathrm{h})$ & 0.98 & very strong \\
\hline
\end{tabular}

$\mathrm{HR}=$ heart rate; VT Vel: ventilatory anaerobic threshold velocity; VT HR $=$ heart rate at the ventilatory anaerobic threshold; $\mathrm{VT} \mathrm{VO}_{2}=$ oxygen consumption at the ventilatory anaerobic threshold; Max velocity = maximum velocity; Max $\mathrm{HR}=$ maximum heart rate; $\mathrm{VO}_{2}$ max $=$ maximum oxygen consumption; $\mathrm{vVO}_{2} \max =$ lowest velocity at which oxygen consumption plateau is observed.

applied focusing on the better selection and preparation of its practitioners.

Our results are close to those reported by Denadai et al. ${ }^{7}$, in terms of the relevance of the $\mathrm{vVO}_{2}$ max variable for athletic performance. The authors inferred that $\mathrm{vVO}_{2}-$ max and the time in which they continued after reaching the $\mathrm{VO}_{2}$ plateau (Tlim) explained $88 \%$ of the variation in endurance athlete performance in a $1500 \mathrm{~m}$ race. This variable was also studied by Guglielmo et al. ${ }^{18}$, who carried out several protocols in nine endurance athletes, in order to identify variables associated with performance in $1500 \mathrm{~m}, 3000 \mathrm{~m}$, and $5000 \mathrm{~m}$ races. $\mathrm{vVO}_{2} \max$ was the only variable that determined performance in $1500 \mathrm{~m}$ and $3000 \mathrm{~m}$ races, showing a negative correlation with time at the different distances $(r=-0.78$ and $r=-0.81$ respectively). In another study issuing this relationship, Souza et al. ${ }^{19}$ conducted track and laboratory tests to predict the performance of middle and long-distance runners. $\mathrm{vVO}_{2}-$ max was the only variable selected to explain performance in $1500 \mathrm{~m}$ and $5000 \mathrm{~m}$ races (62\% and $35 \%$ respectively). Even for amateur athletes, $\mathrm{vVO}_{2} \mathrm{max}$ was found to correlate with running performance ${ }^{20}$. The results of the study of Lourenço et al. ${ }^{20}$ showed a significant and very large negative correlation $(\mathrm{r}=-0,89)$ between $\mathrm{VVO}_{2} \max$ and the time spent for $3000 \mathrm{~m}$ running. The velocity at the ventilatory threshold and the respiratory compensation point also presented this behavior, with almost perfect correlation coefficients, $r=-0.92$ and $r=-0.96$, respectively.

The $\mathrm{VVO}_{2} \max$, the minimum speed at which the maximal $\mathrm{VO}_{2}$ is achieved, is the intensity beyond which there is no additional contribution of the aerobic metabolic system for the additional energy required from the effort. The higher this velocity, the less the athlete will suffer from the acidosis from the anaerobic system utilization even at high absolute intensities. Consequently, she will be able to perform the running task more easily and achieve better results. Due to its remarkable relationship with athletic performance, this variable has been an excellent indicator for prescribing exercise intensity ${ }^{21}$ and has been successfully used for runners and cyclists ${ }^{22}$.
McLaughlin et al. ${ }^{23}$ corroborate the previous explanation when stating that $\mathrm{vVO}_{2} \mathrm{max}$ is a composition of $\mathrm{VO}_{2}$ max and running economy. So, our results are in accordance with the exercise physiology literature and also with studies with other sports modalities, previously described in this paper. It should be noted that those studies were conducted with male subjects, and because of that the comparison and the discussion should be done cautiously. However, due to the validity of the aforementioned studies, the scarcity of research with women, and the similar behavior exhibited by both sexes for $\mathrm{O}_{2}$ kinetics $^{24}$, the results of these studies were considered while discussing our outcomes.

With respect to $\mathrm{VO}_{2} \mathrm{max}$, the present study found no significant relationship between this variable and performance in the $4 \mathrm{~km}$ cross country race, such that athletes with the highest $\mathrm{VO}_{2}$ max values were not necessarily the best runners at the distance analyzed. This corroborates the importance of the concept of running economy instead of maximal cardiopulmonary capacity, especially for elite athletes, which mostly already have very high $\mathrm{VO}_{2}$ max values. Other studies concerning running performance corroborate our results since they also failed to find $\mathrm{VO}_{2} \mathrm{max}$ as an important predictive variable in significant regression models ${ }^{20,25}$.

The present study has some limitations. First of all, the small sample size $(n=05)$, that prevented the use of more robust statistical analysis strategies. It is important to underscore, however, that this is a representative number of Brazilian female military pentathlon athletes, given that there are fewer than 30 women in this population (including Army, Navy, and Air Forces). Furthermore, the target population of the study (Brazilian military pentathlon team) involves six athletes with the best performance in the country, five of whom participated in our study. Another issue that should be better developed is to consider the other four events: shooting, grenade throwing, obstacle running, and obstacle swimming, since one athlete must have high performance in all of them, in addition to the cross country running. 
The findings of the present study may be extremely valuable in the selection process of athletes for the military pentathlon team, given the association observed between performance and these indicators $\left(\mathrm{vVO}_{2} \mathrm{max}\right.$ and maximum velocity). Moreover, they should also be used to monitor the development of athletes on the military pentathlon team in response to the elected training intervention.

Furthermore, we strongly suggest that future studies include longitudinal analysis, monitoring the evolution of race performance and the $\mathrm{vVO}_{2}$ max and maximum velocity, to confirm the present cross-sectional results.

\section{Conclusion}

The results of the present study allow us to conclude that $\mathrm{vVO}_{2} \mathrm{max}$ and maximum velocity are correlated to the performance of military pentathlon athletes in the $4 \mathrm{~km}$ cross-country race. The athletes that achieved the highest values in these indicators covered the race distance in the shortest time, obtaining the highest score in this event.

\section{Acknowledgments}

We would like to acknowledge the Brazilian Army Sports Commission (CDE) for the cooperation for the accomplishment of this study, and also the athletes and their coaches for the participation in the present research.

\section{References}

1. Conseil International du Sport Militaire. Military Pentatlon Regulations, 2020. Available from: https://www.milsport. one/sports/military-pentathlon [Accessed $19^{\text {th }}$ October 2021].

2. Military Pentathlon. $7^{\text {th }}$ Military World Games, 2019. Results team. Available from: https://www.military-pentath lon.info/results/results.php?comp_id=2019-CHN-1 [Accessed: $19^{\text {th }}$ October 2021].

3. Rodrigues A, Perez A, Carletti L, Bissoli N, Abreu G. Valores de consumo máximo de oxigênio determinados pelo teste cardiopulmonar em adolescentes: uma proposta de classificação. J Pediatr. 2006;82(6):426-30. doi

4. Herdy A, Uhlendorf D. Valores de referência para o teste cardiopulmonar para homens e mulheres sedentários e ativos. Arq Bras Cardiol. 2011;96(1):54-9. doi

5. Santos T, Rodrigues A, Greco C, Marques A, Terra B, Oliveira $\mathrm{B}$. $\mathrm{VO}_{2}$ máx estimado e sua velocidade correspondente predizem o desempenho de corredores amadores. Rev Bras Cineantropom Desempenho Hum. 2012;14(2):192-201. doi

6. Billat V, Renoux J, Pinoteau J, Petit B, Koralsztein J. Times to exhaustion at 90,100 and $105 \%$ of velocity at V?O2 max (Maximal aerobic speed) and critical speed in elite long-distance runners. Arch Physiol Biochem. 1995;103(2):129-35. doi

7. Denadai B, Ortiz M, Mello M. Índices fisiológicos associados com a performance aeróbia em corredores de endur- ance: efeitos da duração da prova. Rev Bras Med Esporte. 2004;10(5):401-4. doi

8. Ortiz M, Denadai B, Stella S, de Mello M. Efeitos do treinamento aeróbio de alta intensidade sobre a economia de corrida em atletas de endurance. Rev Bras Cienc Mov. 2003;11(3):53-6. doi

9. Guglielmo L, Greco C, Denadai B. Relação da potência aeróbica máxima e da força muscular com a economia de corrida em atletas de endurance. Rev Bras Med Esporte. 2005;11(1):53-6. doi

10. Junior L, Pinto E, Souza F, Magini M, Martins R. Estudo comparativo do consumo de oxigênio e limiar anaeróbio em um teste de esforço progressivo entre atletas profissionais de futebol e futsal. Rev Bras Med Esporte. 2006;12(6):323-6. doi

11. Mainardi F, Inoue A, Pompeu F, Santos T. Validade preditiva da medida e estimativas do $\mathrm{VO}_{2}$ máx no desempenho de Mountain Bikers. Rev Bras Med Esporte. 2015;21(1):448. doi

12. Balady GJ, Arena R, Sietsema K, Myers J, Coke L, Fletcher GF et al. Clinician's guide to cardiopulmonary exercise testing in adults. Circulation. 2010;122(2):191-225. doi

13. Bragada J, Santos P, Maia J, Colaço P, Lopes V, Barbosa T. Longitudinal study in 3,000 m male runners: the relationship between performance and selected physiological parameters. J Sports Sci Med. 2010;9(3):439-44.

14. Shephard R. La resistencia en el deporte. Barcelona: Editorial Paidotribo; 2007.

15. Borg G. Borg's perceived exertion and pain scales. Illinois: Human Kinetics; 1998.

16. Wasserman K, Hansen J, Sue D, Casaburi R, Whipp B. Prova de esforço-princípios e interpretação. Rio de Janeiro: Revinter; 2005.

17. Callegari-Jacques S. Bioestatística: princípios e aplicações. Porto Alegre: Artmed Editora; 2009.

18. Guglielmo L, Junior R, Arins F, Dittrich N. Índices fisiológicos associados com a performance aeróbia de corredores nas distâncias de 1,5 km, 3 km e 5 km. Motriz: J Phys Ed. 2012;18(4):690-8. doi

19. Souza K, Lucas R, Grossi T, Costa V, Guglielmo L, Denadai B. Predição da performance de corredores de endurance por meio de testes de laboratório e pista. Rev Bras Cineantropom Desempenho Hum. 2014;16(4):466-74. doi

20. Lourenço TF, Silva FOC, Tessutti LS, Silva CE, Abad CCC. Prediction of 3000-m running performance using classic physiological respiratory responses. Int J Kinesiol Sports Sci. 2018;6(3):18-24. doi

21. Cerezuela-Espejo V, Courel-Ibáñez J, Morán-Navarro R, Martínez-Cava A, Pallarés JG. The relationship between lactate and ventilatory thresholds in runners: validity and reliability of exercise test performance parameters. Front Physiol. 2018;9:1320. doi

22. Mendes de Oliveira M, Caputo F, Greco C, Denadai B. Aspectos relacionados com a otimização do treinamento aeróbio para o alto rendimento. Rev Bras Med Esporte. 2010;16(1):61-6. doi

23. McLaughlin JE, Howley ET, Basset DR, Thompson DL, Fitzhugh EC. Test of the classic model for predicting endur- 
ance running performance. Med Sci Sports Exerc. 2010;42 (5):991-7. doi

24. Azevedo P, Oliveira J, Simões H, Baldissera V, Perez S. Cinética do consumo de oxigênio e tempo limite na $\mathrm{vVO}_{2^{-}}$ max: comparação entre homens e mulheres. Rev Bras Med Esporte. 2010;16(4):278-81. doi

25. Scheer V, Janssen TI, Vieluf S, Heitkamp H-C. Predicting trail running performance with laboratory exercise tests and field-based results. Int J Sports Physiol Perform. 2018; 14 (1): 130-133. doi

\section{Corresponding author}

Míriam Raquel Meira Mainenti. Escola de Educação Física do Exército, Rio de Janeiro, RJ, Brazil.

E-mail: miriam.mainenti@hotmail.com.

Manuscript received on October 30, 2021

Manuscript accepted on November 7, 2021

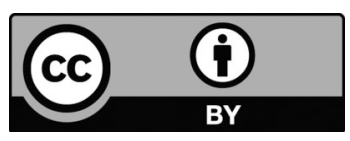

Motriz. The Journal of Physical Education. UNESP. Rio Claro, SP, Brazil - eISSN: 1980-6574 - under a license Creative Commons - Version 4.0 